\title{
Spatial Relationships between COVID-19 infection rates and Air Pollution, Geo-Meteorological and Social Parameters in Dhaka, Bangladesh
}

\author{
Md. Shareful Hassan ( $\square$ shareful@gmx.com ) \\ 4668-2951 \\ Mohammad Amir Hossain Bhuiyan1 \\ Department of Environmental Sciences, Jahangirnagar University, Dhaka, 1342, Bangladesh

\section{Saikat Mandal Tanu} \\ Department of Geography and Environment, Jahangirnagar University, Dhaka, 1342, Bangladesh

\section{Md. Faysal Tareq} \\ Institute of Energy, University of Dhaka, Dhaka, 1000, Bangladesh \\ Md. Bodrud-Doza \\ Climate Change Programme, BRAC Bangladesh

\section{K. A. Rabbani} \\ Department of Environmental Science and Management, Independent University Bangladesh (IUB)
}

Department of Environmental Sciences, Jahangirnagar University, Dhaka, 1342, Bangladesh https://orcid.org/0000-0003-

\section{Research Article}

Keywords: COVID-19, Dhaka city, Bangladesh, GIS, Geographically Weighted Regression (GWR)

Posted Date: June 30th, 2020

DOI: https://doi.org/10.21203/rs.3.rs-39091/v1

License: (c) (i) This work is licensed under a Creative Commons Attribution 4.0 International License. Read Full License 


\section{Abstract}

Like all infectious diseases, the infection rate of COVID-19 is dependent on many variables. Geographically Weighted Regression (GWR) model and GIS was used to understand the associations between COVID-19 infection rate as a dependent variable and 17 independent variables of air pollution, geo-meteorological and social parameters using a set of temporal data from 2010-2020 (May) in Dhaka, Bangladesh. This study revealed that air pollution parameters like $\mathrm{PM}_{2.5}(p<0.02), \mathrm{AOT}$ $(p<0.01)$, $\mathrm{CO}(p<0.05)$, water vapor $(p<0.01)$ and $\mathrm{O}_{3}(p<0.01)$ were highly correlated with COVID-19 infection rate while geometeorological parameters like DEM $(p<0.01)$, wind pressure $(p<0.01)$, LST $(p<0.04)$, rainfall $(p<0.01)$ and wind speed $(p<0.03)$ were also similarly associated . Social parameters like population density $(p<0.01)$, brickfield density $(p<0.02)$, and poverty level $(p<0.01)$ showed high coefficients as the key independent variables to COVID-19 infection rate. Geographically, significant robust relationships of these factors were found in the middle and southern parts of the city where the reported infection case was also higher. Relevant agencies can utilize these findings to formulate new and smart rules or strategies for reducing infectious diseases like COVID-19 in Dhaka and in similar urban cities around the world.

\section{Introduction}

In December 2019, the first reported cases of a new infectious disease were found in Wuhan, China (Guan et al. 2020). It was named as COVID-19, a new virus of the group of coronaviridae, which is also known as severe acute respiratory Syndrome Coronavirus 2 (SARS-CoV-2) (Gorbalenya 2020; Pedrosa 2020). The typical clinical symptoms include fever, dry cough, myalgia, and pneumonia which may cause progressive respiratory failure due to alveolar damage and may eventually lead to death (Huang et al. 2020). On $11^{\text {th }}$ March 2020, the World Health Organization (WHO) has declared the COVID-19 as a public health emergency because the number of cases drastically increased outside of China (World Health Organization 2020). As of May 20, 2020, 4,900,255 confirmed cases in over 200 countries/regions and 323,341 deaths were reported worldwide (Johns Hopkins University 2020).

Like other countries, Bangladesh is also suffering from this global pandemic. Bangladesh has a population of more than 163.7 million with a population density of $1,265 / \mathrm{km}^{2}$ making it one of the most densely populated countries in the world (Bangladesh Population 2020). Almost 37.4\% of its total population lives in urban areas with a high level of air pollution (Bangladesh - Urban population 2019). Most Bangladeshi urban areas, specially its capital Dhaka, are highly exposed to different types of air pollutants e.g. $\mathrm{PM}_{2.5}, \mathrm{PM}_{10}, \mathrm{COx}, \mathrm{NOx}, \mathrm{SOx}$, dust, and others because of uncontrolled urbanization, industrial emissions, high traffic density and construction activities. Air pollution is considered as one of the key threats for public health (Begum et al. 2013; Hassan et al. 2019; Imran et al. 2014; Tusher et al. 2018) and Dhaka has consistently been one of the top five most polluted cities of the world for the last several years (Shibli 2019). Because high population density and high pollution levels have an adverse effect on public health, the residents of Dhaka are highly susceptible to the risk of COVID-19 infection. As of May 22, 2020, according to the Institute of Epidemiology, Disease Control and Research (IEDCR), Bangladesh reported 28,521 confirmed cases with total death of 408 in the whole country. The majority of the confirmed cases were identified in Dhaka which is also the epicenter of this infectious disease and till now there have been 12,386 confirmed cases reported with 103 deaths (Bangladesh Covid-19 Update 2020).

Research investigating the relationships between COVID-19 infection rate and air pollution are starting to appear in the literature ((He et al. 2020) (Bontempi 2020)). A regional study in four countries of Europe to examine the relationship between $\mathrm{NO}_{2}$ and the number of fatalities due to COVID-19 showed that long-term exposure to $\mathrm{NO}_{2}$ may be one of the most important contributors to fatality caused by the virus(Ogen 2020). Researchers in Italy have speculated that atmospheric pollution is a co-factor in inducing high levels of deaths due to COVID-19 (Conticini et al. 2020; Martelletti and Martelletti 2020). A nationwide cross-sectional study in the United States considering 20 confounding factors including population density, weather and socioeconomic variables showed that $\mathrm{PM}_{2.5}$ had a clear link to COVID-19 mortality rates (Wu et al. 
2020a). (Conticini et al. 2020) have suggested considering population, social habits and meteorological condition together with air pollution when analyzing COVID-19 spread and mortality rates. However, caution is recommended by (Bontempi 2020), who have shown that there is no strong evidence that COVID-19 diffusion mechanism occurs through the air using $\mathrm{PM}_{10}$ as a carrier (Bontempi 2020) even though $\mathrm{PM}_{10}$ was shown to have a functional linear relationship with cardiovascular disease and non-accidental mortality rate in Spain (Ortiz et al. 2017). An 11 city study was conducted in China where nonlinear models were employed to investigate the relationship between non-accidental mortality and $\mathrm{NO}_{2}, \mathrm{PM}_{2.5}$, temperature and relative humidity as covariates (He et al. 2020). The researchers found higher effect estimates of intermediate-term $\mathrm{NO}_{2}$ exposure on respiratory mortality compared to that of the short-term but the differences were too small to be considered statistically significant. (Bontempi 2020) also mentioned that the airborne diffusion of COVID-19 is affected by the local air particulate matter (PM) in northern Italy but finds that there is no significant relationship between $\mathrm{PM}_{10}$ and COVID-19 mortality rates.

There have also been studies relating to COVID-19 infection rates and geo-meteorological parameters. Temperature, humidity, and rainfall may have a direct influence to spread the COVID-19 and other infectious vector-borne diseases (Casanova et al. 2010; Qi et al. 2020). (Xie and Zhu 2020) conducted a study in 122 cities across China to establish epidemiological and experimental research on ambient temperature and COVID-19 infection. Their exposure-response curve recommended that the mean temperature and COVID-19 confirmed cases are significant. Surrounding temperature is an essential factor to affect the transmission and survival of coronavirus (Xie and Zhu 2020). Humidity, wind speed, and temperature are inversely associated with the infection rate of the COVID-19 in 310 areas from 116 countries. (Nazrul Islam 2020) conducted this research and found that both cold and dry environments were favorable to the spread of COVID-19. (Xie and Zhu 2020) found a negative linear relationship between the COVID-19 confirmed cases and mean temperature in 122 cities in mainland China, suggesting warmer weather will not be a crucial factor to reduce the infection case of COVID19. On the contrary, higher mean temperature and average relative humidity are quite significant in enhancing the COVID-19 contamination rate in Brazil (Auler et al. 2020) although average temperature and relative humidity were not consistent in terms of geographical areas, because of spatial heterogeneity problems (Qi et al. 2020). (Bashir et al. 2020) found a positive relationship between the COVID-19 and average temperature, minimum temperature, and air quality in New York, USA. Although they found a negative relationship with rainfall. (Hu et al. 2013) assumed that the transmissibility of an infectious disease is totally dependent on the population density of an area. They found that lower population density has the lower reported cases of an infectious disease than the higher density locations. There are other results revealed and concluded that population density is one of the key factors to control the COVID-19 (Luo et al. 2020; Pedrosa 2020; Sajadi et al. 2020). Integration of environmental, climatic, biodiversity, and man-made factors are useful for analyzing and predicting vectorborne and infectious diseases (Ceccato et al. 2018).

Based on the above discussion the factors influencing COVID-19 infection rates can classify into three categories: air pollution parameters, geo-meteorological parameters and social parameters. This study will use 17 independent variables of air pollution, geo-meteorological and social data against the COVID-19 infection rate using Geographic Information System (GIS) and an advanced statistical tool of Geographically Weighted Regression (GWR). Considering these variables and methodologies, this study aims to understand the spatial relationships between the infection rate of COVID-19 and air pollution, geo-meteorological, and social parameters in Dhaka, Bangladesh.

\section{Materials And Methods}

\section{Study location}

The study area is located in Dhaka (or Dhaka Metropolitan Area) as the administrative and financial capital of Bangladesh

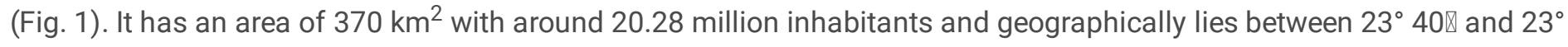
$54 \otimes N$ latitude and $90^{\circ} 20 \otimes$ and $90^{\circ} 28 \otimes \mathrm{E}$ longitude (Ahmed et al. 2013; Hoque et al. 2007). Geographically Dhaka city is located in the lower reaches of the Ganges Delta on the tributary of the Meghna Ganges river system (Ahmed et al. 2014). 
The monthly average temperature ranges from 25 to $31^{\circ} \mathrm{C}$, the mean relative humidity and evaporation range between 80 and $90 \%$ and $80-130 \mathrm{~mm}$, respectively (BMD 2016). The topography of the city is relatively flat and its elevation varies between 0.5 and 12 meters (Hoque et al. 2007). Therefore, this study area is considered as a hotspot to test the relationship between the COVID-19 infection rate and 17 parameters in this study.

\section{COVID-19 data}

Daily Thana (police precinct) wise COVID-19 infection rate was used from two government sources in this study (Table 1). This database was entered into a city GIS shapefile for further statistical and spatial analyses. Death statistics of COVID-19 data was not possible to collect because these are not yet publicly available at the time of writing this paper (May 23, 2020).

\section{Collection of sample points}

86 random sample points were collected from different parts of the study area. During this point data selection and collection, some basic guidelines were followed considering the main objective of the study and data variation due to multisources such as infection rate of COVID-19, population density, urban morphology, patterns of the residential area, high traffic zone, industrial area, high- and low-income zones, land use, etc. (Fig.1). On-screen digitization process was used to extract these points from different locations of the study area with the help of high-resolution Google map and a combination of other relevant secondary data.

\section{Air pollution parameters}

7 air pollution parameters, namely particulate matter $\left(\mathrm{PM}_{2.5}\right)$, nitrogen dioxide $\left(\mathrm{NO}_{2}\right)$, Aerosol Optical Thickness (AOT), sulphur dioxide $\left(\mathrm{SO}_{2}\right)$, carbon monoxide (CO), water vapor and ozone $\left(\mathrm{O}_{3}\right)$ of the period 2010-2020 (May) were used in this study (Table 1). The annual average of high-resolution atmospheric data from different satellites was analyzed to derive spatial maps of each parameter because satellite-based air quality mapping and monitoring in urban areas have been advent as a new avenue of atmospheric research (Engel-Cox et al. 2004). After pre and post-processing all of the temporal air pollution parameters, the digital number of each parameter was extracted for 86 sample points. Finally, seven different maps of the annual average concentration of each parameter were generated using a point interpolation method of spatial analysis technique.

\section{Geo-meteorological parameters}

The raster data of the digital elevation model or DEM $(\mathrm{m})$, wind pressure $\left(\mathrm{ms}^{-1}\right)$, rainfall $(\mathrm{mm})$, land surface temperature or LST $\left({ }^{\circ} \mathrm{C}\right)$, and wind speed ( $\mathrm{mph}$ ) were collected from different sources and satellite information (Table 1). These geo-rectified data were analyzed using GIS platform and finally resampled into 30-meter resolution in order to make an alignment with land use resolution. Finally, four different maps of the annual average concentration of each parameter generated using spatial analysis technique, while the DEM had only 1-year data.

\section{Social parameters}

Both vector and raster databases were used to classify the social variables (Table 1). All the vector data, after converting into raster datasets, rasterized to 30-meter resolution keeping GCS-WGS-1984 and D-WGS-1984 geographic coordinate system and datum respectively. On-screen digitization process was used for collecting brickfield points in the study area using highresolution Google map. Brickfield density was included in the model because brick kilns are considered one of the main 
sources of air pollution in Dhaka (Guttikunda et al. 2013a). Thana wise literacy data from the Bangladesh Bureau of Statistics was used to assign points into Dhaka city map digitally to perform further analysis.

Table 1 Characteristics of different databases used in the study

\begin{tabular}{|c|c|c|c|c|}
\hline Theme & $\begin{array}{l}\text { Parameters } \\
\text { (Independent) }\end{array}$ & Unit & Data sources & $\begin{array}{l}\text { Temporal/data } \\
\text { year }\end{array}$ \\
\hline \multirow{7}{*}{ Air pollutants } & $\mathrm{PM}_{2.5}$ & $\mu \mathrm{g} / \mathrm{m}^{3}$ & $\begin{array}{l}\text { https://sedac.ciesin.columbia.edu/ } \\
\text { https://www.ecmwf.int/en/forecasts/accessing- } \\
\text { forecasts }\end{array}$ & $\begin{array}{l}2010-2020 \\
\text { (April) }\end{array}$ \\
\hline & $\mathrm{NO}_{2}$ & $\mathrm{~nm}^{2}$ & https://aura.gsfc.nasa.gov/ & $\begin{array}{l}\text { 2010-2020 } \\
\text { (April) }\end{array}$ \\
\hline & AOT & & https://neo.sci.gsfc.nasa.gov/ & $\begin{array}{l}\text { 2010-2020 } \\
\text { (April) }\end{array}$ \\
\hline & $\mathrm{SO}_{2}$ & ppm & https://search.earthdata.nasa.gov/search & $\begin{array}{l}\text { 2019-2020 } \\
\text { (April) }\end{array}$ \\
\hline & $\mathrm{CO}$ & ppm & https://search.earthdata.nasa.gov/search & $\begin{array}{l}\text { 2010-2020 } \\
\text { (April) }\end{array}$ \\
\hline & Water Vapor & $\mathrm{cm}$ & https://www.worldclim.org/data/worldclim21.html & $\begin{array}{l}2010-2020 \\
\text { (April) }\end{array}$ \\
\hline & $\mathrm{O}_{3}$ & ppm & https://search.earthdata.nasa.gov/search & $\begin{array}{l}\text { 2010-2020 } \\
\text { (April) }\end{array}$ \\
\hline \multirow{5}{*}{$\begin{array}{l}\text { Geo- } \\
\text { meteorological }\end{array}$} & DEM & Meter & https://search.earthdata.nasa.gov/search & 2019 \\
\hline & Wind pressure & $\mathrm{m} \mathrm{s}^{-1}$ & https://www.worldclim.org/data/worldclim21.html & $\begin{array}{l}2010-2020 \\
\text { (April) }\end{array}$ \\
\hline & LST & ${ }^{\circ} \mathrm{C}$ & https://search.earthdata.nasa.gov/search & $\begin{array}{l}\text { 2010-2020 } \\
\text { (April) }\end{array}$ \\
\hline & Rainfall & $\mathrm{mm}$ & https://gpm.nasa.gov/trmm & $\begin{array}{l}\text { 2010-2020 } \\
\text { (April) }\end{array}$ \\
\hline & Wind speed & $\mathrm{mph}$ & https://www.worldclim.org/data/worldclim21.html & 2017 \\
\hline \multirow{5}{*}{ Social } & Population density & Per dot & Bangladesh Bureau of Statistics & 2011 \\
\hline & Brickfield & Meter & Direct digitization & 2019 \\
\hline & Poverty & $\%$ & https://data.humdata.org/ & 2017 \\
\hline & Land use & Class & Landsat 8 & 2019 \\
\hline & Literacy & $\%$ & Bangladesh Bureau of Statistics & 2011 \\
\hline $\begin{array}{l}\text { Dependent } \\
\text { variable }\end{array}$ & $\begin{array}{l}\text { COVID-19 } \\
\text { infection/mortality }\end{array}$ & $\begin{array}{l}\text { Upazila } \\
\text { Wise }\end{array}$ & $\begin{array}{l}\text { Bangladesh Ministry of Health } \\
\text { https://www.iedcr.gov.bd/ }\end{array}$ & 2020 (May) \\
\hline
\end{tabular}

Geographically Weighted Regression (GWR) 
Geographically Weighted Regression (GWR) method was used to map the association between ambient air pollution, geometeorological and social data with the COVID-19 infection rate. Geographically Weighted Regression (GWR) is an approach of exploring spatial non-stationary which permits different relationships to exist at different points in space by the process of calibrating several regression models in a systematic process (Leung et al. 2000). The fundamental principle of GWR is that parameters may be estimated anywhere in the study area given a dependent variable and a set of one or more independent variables that have been measured at places whose location is known(Charlton et al. 2009; Fotheringham et al. 1998). GWR offers the potential of investigating relationships that vary over space between variables in a regression model and it is quite a handy approach that allows complex spatial variations in parameter estimates to be identified, mapped, and modeled (Brunsdon et al. 1996; Wheeler and Páez 2010). In the GWR model component, $X$ is a matrix containing a set of independent or predictor variables and $\mathrm{Y}$ is a vector of dependent or response variables. The main calculation of this model is in equation 1.

\section{$Y=\beta_{o}+\beta_{1} X_{1}+\beta_{2} X_{2}+\ldots \ldots . . \beta_{n} X_{n}+\bigotimes$}

Where $Y$ is the dependent variable, $\beta_{0} \ldots . . \beta_{n}$. are regression coefficients, $X_{1} \ldots X_{n}$ is the independent variables and $\nabla$ is the residuals error. In this study, Geographically Weighted Regression model was used for air pollution, geo-meteorological, and social parameters individually and each run were done in triplicate. These main GWR calculations for the models are given below-

For air pollution parameters:

\section{$\operatorname{COVID}-19(\mathrm{Y})=\beta_{\mathrm{o}}+\beta_{1}\left(\mathrm{PM}_{2.5}\right)+\beta_{2}\left(\mathrm{NO}_{2}\right)+\beta_{3}(\mathrm{AOT})+\beta_{4}\left(\mathrm{SO}_{2}\right)+\beta_{5}(\mathrm{CO})+\beta_{6}(\mathrm{WV})+$

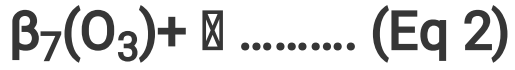

For geo-meteorological parameters:

\section{COVID-19 $=\beta_{\mathrm{o}}+\beta_{1}(\mathrm{DEM})+\beta_{2}(\mathrm{WP})+\beta_{3}($ LST $)+\beta_{4}($ Rainfall $)+\beta_{5}($ Wind speed $)+$ $\triangle \ldots \ldots \ldots \ldots \ldots . . . . . . . . . . . . . . .(E q ~ 3)$}

For social parameters:

\section{COVID-19 $(Y)=\beta_{\circ}+\beta_{1}$ (Pop density) $+\beta_{2}$ (Brickfield $)+\beta_{3}$ (Poverty) $+\beta_{4}$ (Land use $)+\beta_{5}($ Literacy) + 囚......... (Eq 4)}

After executing these 3 models, the resultant databases were exported and the coefficient, standard error, T, $p$-value, and $r^{2}$ wereinput into ArcGIS software for deriving some spatial maps using a point interpolation method.

\section{Point interpolation using Inverse Weighted Distance (IWD)}

Inverse Weighted Distance (IWD) method was used for point data interpolation because this multivariate method is very useful for temporal climate and environmental data analysis (Chen and Liu 2012). This interpolation method simply creates an assumption that close points from a known point are more identical than those points are staying apart (Esri 2020). To measure the predicted value of each point location, IDW assigns some weights based on the closest distance from a known point. The weights can be expressed as- 


$$
\lambda_{j}=\left(\frac{1}{{ }_{d}^{P}}\right) /\left(\sum_{i}^{n}=1 \frac{1}{{ }_{d}^{P}}\right)
$$

Where $d_{i}$ is the distance between known and unknown points, $\mathrm{p}$ is the power parameter, and $\mathrm{n}$ represents the number of sampled points used for the estimation. The main factor affecting the accuracy of IDW is the value of the power parameter (p) and the search of the neighborhood (Babak and Deutsch 2009; Franke 1982; Shepard 1968).

All the mapping exercises and graphical presentations were done using ArcGIS and Excel software respectively. The relevant shapefile (Upazila vector) was collected from the Bangladesh Local Government and Engineering Department, while the land use map of the city was processed by one of the authors of the paper.

\section{Results}

\section{COVID-19 infection rate}

As of May 22, 2020, about 6,245 COVID-19 cases were confirmed in Dhaka city. The graph shows that this virus infection has affected all areas of the city and the increase in cases from May 06 to May 18, 2020 (Fig. 2).

\section{Descriptive statistical analysis of all parameters}

The annual average concentrations of air pollution, geo-meteorological, and social parameters showed in Table 2. The mean annual average concentration of $\mathrm{PM}_{2.5}\left(83.98 \mu \mathrm{g} / \mathrm{m}^{3}\right), \mathrm{NO}_{2}\left(427.29 \mathrm{~nm}^{2}\right), \mathrm{SO}_{2}(89.18 \mathrm{ppm}), \mathrm{CO}(93.10 \mathrm{ppm})$, and $\mathrm{O}_{3}(238.40$ ppm) were above the national level threshold. The minimum and maximum range of digital elevation model and land surface temperature were $6-14$ meters and $20-27^{\circ} \mathrm{C}$ respectively. The mean annual rainfall and wind speed were $275 \mathrm{~mm}$ and $0.96 \mathrm{mph}$ respectively in the study area. In the social parameters, 0-1878 per person found per square kilometer while the mean poverty and literacy rates were $70 \%$ and $74 \%$ respectively.

Table 2 The annual average of the key variables used in this study 


\begin{tabular}{|c|c|c|c|c|c|c|c|c|}
\hline Theme & Variables & Mean & $\begin{array}{l}\text { Std } \\
\text { Error }\end{array}$ & $\begin{array}{l}\text { Standard } \\
\text { Deviation }\end{array}$ & Range & Min & Max & Sum \\
\hline \multirow{7}{*}{$\begin{array}{l}\text { Air pollution } \\
\text { parameters }\end{array}$} & $\mathrm{PM}_{2.5}$ & 83.98 & 0.04 & 0.40 & 2.05 & 83.06 & 85.11 & 7222.66 \\
\hline & $\mathrm{NO}_{2}$ & 427.29 & 1.86 & 17.21 & 83.95 & 373.87 & 457.82 & 36746.62 \\
\hline & AOT & 0.45 & 0.00 & 0.01 & 0.05 & 0.42 & 0.46 & 38.46 \\
\hline & $\mathrm{SO}_{2}$ & 89.18 & 1.02 & 9.43 & 41.87 & 47.24 & 89.11 & 5089.84 \\
\hline & $\mathrm{CO}$ & 93.10 & 0.02 & 0.15 & 0.78 & 92.94 & 93.72 & 8006.90 \\
\hline & $\begin{array}{l}\text { Water } \\
\text { vapor }\end{array}$ & 2.39 & 0.00 & 0.00 & 0.00 & 2.39 & 2.39 & 205.54 \\
\hline & $\mathrm{O}_{3}$ & 238.40 & 0.02 & 0.23 & 0.87 & 237.96 & 238.83 & 20502.62 \\
\hline \multirow{5}{*}{$\begin{array}{l}\text { Geo-meteorological } \\
\text { parameters }\end{array}$} & DEM & 9.83 & 0.25 & 2.27 & 8.02 & 6.20 & 14.22 & 845.33 \\
\hline & $\begin{array}{l}\text { Wind } \\
\text { pressure }\end{array}$ & 2.00 & 0.01 & 0.07 & 0.26 & 1.88 & 2.14 & 172.37 \\
\hline & LST & 26.17 & 0.01 & 0.10 & 0.46 & 25.87 & 26.33 & 2250.39 \\
\hline & Rainfall & 275.89 & 2.13 & 19.79 & 72.19 & 240.05 & 312.24 & 23726.29 \\
\hline & $\begin{array}{l}\text { Wind } \\
\text { speed }\end{array}$ & 0.56 & 0.00 & 0.04 & 0.10 & 0.50 & 0.60 & 48.26 \\
\hline \multirow[t]{5}{*}{ Social parameters } & $\begin{array}{l}\text { Pop } \\
\text { density }\end{array}$ & 336.15 & 37.79 & 350.42 & 1878.00 & 0.00 & 1878.00 & 28909.32 \\
\hline & Brickfield & 60.39 & 2.33 & 21.62 & 96.52 & 15.48 & 112.00 & 5193.29 \\
\hline & Poverty & 69.73 & 0.23 & 2.16 & 10.27 & 64.62 & 74.89 & 5996.87 \\
\hline & Land use & 2.91 & 0.11 & 1.04 & 4.00 & 1.00 & 5.00 & 250.00 \\
\hline & Literacy & 73.81 & 0.71 & 6.58 & 29.00 & 57.00 & 86.00 & 6348.00 \\
\hline
\end{tabular}

\section{Geographical Weighted Regression (GWR) parameters}

Three Geographical Weighted Regression models were executed in order to understand the statistics and spatial relationships between the COVID-19 infection rate (dependent variable) and the 17 independent variables of air pollution, geo-meteorological and social data. After running these multi-regression models, significant model fitting results such as estimated coefficient, standard error, T, p-value, and $\mathrm{r}^{2}$ in the 3 sets of parameters are listed (Table 3 ).

In the air pollution data, $\mathrm{PM}_{2.5}(0.64), \mathrm{NO}_{2}(0.11)$, AOT $(0.81), \mathrm{SO}_{2}(0.20)$, and $\mathrm{O}_{3}(2.25)$ parameters had positive values while $\mathrm{CO}(-0.56)$ and water vapor (-3.04) had negative coefficient values. Standard error calculates the distance between each of the data points and its predicted value in a model. The model used in this study estimated a very small standard error in all independent variables (less than 1). There were only 2 negative parameters $C O(-1.9)$ and water vapor $(-3.89)$ found in the T result. Among the 7 air pollution parameters, 5 were statistically significant $\left(r^{2}\right)$ to the COVID -19 infection rate. PM $2.5, A O T$, and $\mathrm{O}_{3}$ statistically posed a significant positive effect on the COVID-19 infection rate at a 95\% confidence level. On the other hand, $C O$ and wind vapor had negative coefficient with the COVID-19, but interestingly both of them were statistically significant at $p-0.01$. These results assumed that a 1 unit increase in the 5 parameters may increase the COVID-19 attack 
or mortality rates in Dhaka City. This model calculated a strong $r^{2}(0.84)$, which indicates that $84 \%$ of the COVID-19 attack is explained by the 7 air pollution parameters.

5 parameters were used for the geo-meteorological data, of which only water pressure $(-0.260)$ had a negative coefficient value. All other parameters like DEM (0.361), LST (0.236), rainfall (0.439), and wind speed $(0.212)$ had a positive influence on the dependent variable by showing a robust $\mathrm{r}^{2}(0.73)$. This model explained about $73 \%$ variation in the independent variables responsible for COVID-19 infection rates. All values extracted from the standard error showed in the normal range while the water pressure $(-1.60)$ was negative in T result. Moreover, among the 5 geo-meteorological parameters, DEM $(p<0.01))$, LST $(p<0.04)$, rainfall $(p<0.07)$, and wind speed $(p<0.03)$ were statistically significant with the COVID-19 infection rate. Therefore, these parameters have the potential to influence the infection of COVID-19 in Dhaka.

Poverty had negative values in the estimated coefficient $(-0.283)$ and T result $(-2.382)$, although it was statistically significant $(p<0.01)$.. On the other hand, population density, brickfield density, land use, and literacy rate had positive results in both the estimated coefficients and T results. These 4 parameters showed a very small standard error, showing these accounted for $70 \%$ of the COVID-19 infection rate $\left(r^{2}=0.70\right)$ in this model. However, the other 2 social parameters like population density $(p<0.01)$ and brickfield $(p<0.02)$ were statistically significant in this regression model. Land use and literacy rate were not statistically significant.

Table 3 Model fitting results of Geographical Weighted Regression Model

\begin{tabular}{|c|c|c|c|c|c|c|}
\hline \multirow[t]{2}{*}{ Theme } & \multirow{2}{*}{$\begin{array}{l}\text { Parameters } \\
\text { (Independent) }\end{array}$} & \multicolumn{5}{|c|}{ Model fitting results (COVID-19 as dependent variable) } \\
\hline & & Estimated coefficient & Standard error & $\mathrm{T}$ & p-value & $\mathrm{R}^{2}$ \\
\hline \multirow{7}{*}{ Air pollutant } & $\mathrm{PM}_{2.5}$ & 0.645 & 0.295 & 2.187 & 0.029 & \multirow{7}{*}{.84} \\
\hline & NO & 0.112 & 0.305 & 0.368 & 0.713 & \\
\hline & AOT & 0.816 & 0.322 & 2.531 & 0.011 & \\
\hline & $\mathrm{SO}_{2}$ & 0.200 & 0.416 & 0.481 & 0.630 & \\
\hline & $\mathrm{CO}$ & -0.562 & 0.296 & -1.900 & 0.057 & \\
\hline & Wind Vapor & -3.043 & 0.784 & -3.881 & 0.015 & \\
\hline & $\mathrm{O}_{3}$ & 2.257 & 0.556 & 4.059 & 0.013 & \\
\hline \multirow{5}{*}{ Geo-meteorological } & DEM & 0.361 & 0.105 & 3.428 & 0.012 & \multirow{5}{*}{.73} \\
\hline & Wind Pressure & -0.260 & 0.162 & -1.604 & 0.015 & \\
\hline & LST & 0.236 & 0.126 & 1.883 & 0.040 & \\
\hline & Rainfall & 0.439 & 0.163 & 2.693 & 0.017 & \\
\hline & Wind speed & 0.212 & 0.102 & 2.077 & 0.038 & \\
\hline \multirow{5}{*}{ Social } & Pop density & 0.318 & 0.116 & 2.738 & 0.016 & \multirow{5}{*}{.70} \\
\hline & Brickfield & 0.212 & 0.095 & 2.233 & 0.026 & \\
\hline & Poverty & -0.283 & 0.119 & -2.382 & 0.017 & \\
\hline & Land use & 0.165 & 0.104 & 1.591 & 0.112 & \\
\hline & Literacy & 0.047 & 0.098 & 0.481 & 0.630 & \\
\hline
\end{tabular}




\section{Spatial Relationship between the COVID-19 infection rate and air pollution, geo- meteorological and social parameters}

In order to understand the different spatial relationships among these factors through the advanced statistical lens, $\mathrm{r}^{2}$, influence, and the $p$ values were derived from the Geographically Weighted Regression (GWR) model. The minimum and maximum $r^{2}$ values were 0.30 and 0.84 in the air pollution parameters respectively (Fig. 3, Map a). The mean value was 0.39 which was mostly found in the south and middle zones of the study area. On the other hand, the mean $r^{2}$ value $(0.28)$ of geometeorological parameters was found in the middle, middle eastern, and southern parts of the study area keeping minimum and maximum values 0.18 and 0.73 respectively (Fig. 3, Map c). The social parameters were important predictors for establishing a relationship with the COVID-19 infection rate. The mean $r^{2}$ value $(0.27)$ was found in the middle, middle eastern, and north-western parts of the study area (Fig. 3, Map b). Whilst its standard deviation was 0.04, the minimum and maximum values were 0.21 and 0.70 respectively.

The higher influence values of independent variables predict a good explanation for the dependent variable. In air pollution parameters, a number of influence zones in the north, eastern, western, and a few in the southern parts were found (Fig. 3, Map a). Except for the middle part of the study area, the influence statistics was quite significant across the study area keeping 0.13 and 0.03 in mean and standard deviation respectively. The influence of geo-meteorological parameters was significantly higher in the study area; except Cantonment, Gulshan, Ramna, Kafrul, Shahbag, Bangshal, Chakbazar, Gendaria and Shyampur areas (Fig. 3, Map c). The minimum and maximum values of geo-meteorological parameters were 0.07 and 0.13 respectively while its mean value was 0.09 . Social parameters were quite influential in the north-eastern and southern parts. The minimum and maximum values of social parameters were 0.06 and 0.21 respectively, while the mean value was 0.10 (Fig. 3, Map b). A strong influence of social parameters was found in the southern part of the city.

The $p$-value is an important parameter in this study. There were some strong relationships between COVID-19 infection rates data and air pollution, geo-meteorological, and social parameters. Strong statistical evidence of $p$ values in $\mathrm{PM}_{2.5}(<0.02)$, AOT (<0.01), $\mathrm{CO}(<0.05)$, water vapor $(<0.01)$, and $\mathrm{O}_{3}(<0.01)$ in the air pollution parameters were found. Most of these parameters and their correlated $p$-values were found in the middle, south, south-western, and south-eastern parts of the study area. Interestingly, $\mathrm{O}_{3}, \mathrm{AOT}$, and wind vapor were found their strong prevalence over the whole study area (Fig. 5).

A number of geo-meteorological parameters selected in this model had some positive relationships with the COVID-19 infection rate. Digital elevation model (DEM), land surface temperature (LST), rainfall and wind speed had statistically significant $p$-values of $<0.01,<0.04,0.01$ and $<0.03$ respectively. Fig. 6 . showed a spatial distribution of $r^{2}$ map in all of the geo-meteorological parameters in where DEM, LST, wind speed, and wind pressure were found in the south, middle, middle eastern and southern parts in the area, respectively. Rainfall had a great statistical influence on the dependent variable, which covered $90 \%$ of the study area.

Population density $(p<0.01)$, brickfield $(p<0.02)$,, and poverty $(p<0.01)$ had significant roles on COVID-19 infection rate in the study area. In terms of the geographical distribution of population density and poverty, about $90 \%$ of areas were covered by these factors (Fig. 7). On the other hand, brickfield was highly visible in the southern part of the study area in which the COVID-19 infection rate was higher. Land use and literacy rate were not statistically significant, but these had a positive coefficient with the dependent variable.

\section{Discussion}

The main objective of this study was to investigate the spatial relationships between COVID-19 infection rate and air pollution, geo-meteorological, and social parameters in the study area using Geographical Weighted Regression and spatial analysis of GIS. Different results from the 3 models and its 17 parameters of 3 thematic areas were found. 


\section{COVID-19 infection rate and air pollution parameters}

Out of 7 air pollution parameters, 5 parameters $\mathrm{PM}_{2.5}(p<0.02)$, AOT $(p<0.01)$, $\mathrm{CO}(p<0.05)$, water vapor $(p<0.01)$, and $\mathrm{O}_{3}$ $(p<0.01)$ were highly correlated with COVID-19 infection rate in this study. These pollutants are highly associated with the impacts on urban public health in Dhaka (Begum et al. 2013). Since COVID-19 mainly causes respiratory failure, it is no surprise that air pollution has an influence on COVID-19 infection rates. (Wu et al. 2020b) used temporal PM 2.5 data from 2000-2016 and the COVID-19 mortality rate for executing a negative binomial mixed model in order to calculate the mortality rate ratio (MRR) in the USA. They found that $1 \mu \mathrm{g} / \mathrm{m}^{3}$ increases of $\mathrm{PM}_{2.5}$ can enhance $8 \%$ of COVID-19 death with a 95\% confidence interval in Mid-Atlantic, upper Midwest, and Gulf Coast areas. In this study, $\mathrm{PM}_{2.5}$ had a significant positive correlation with COVID-19 ( $p<0.02)$ with a 95\% confidence level. Along with other particulates, $\mathrm{PM}_{10}, \mathrm{NO}_{2}$, and $\mathrm{O}_{3}$ were found as critical factors that attribute to mortality in Spain, in which relative risks (RRs) were connected with higher respiratory cases with $\mathrm{Cl} 95 \%$ (Ortiz et al. 2017). $\mathrm{O}_{3}$ ( $p<0.01$ ) was found as a strong factor that may influence the COVID-19 infection rate in this study. It is known that ozone generates oxidative stress and exposure to high ozone concentrations might reduce the lung lining fluid antioxidant level (Domingo and Rovira 2020; Manisalidis et al. 2020). $\mathrm{SO}_{2}$ and $\mathrm{NO}_{2}$ did not show strong correlation and this may be due to slight increases in these pollutants during the pandemic. (Sharma et al. 2020) looked at 5 air pollutants $\left(\mathrm{PM}_{10}, \mathrm{PM}_{2.5}, \mathrm{CO}, \mathrm{NO}_{2}\right.$, and $\left.\mathrm{SO}_{2}\right)$ in India during their lockdown period. They found these parameters had significant contribution to reducing the Excessive Risks (ER) due to COVID-19 mortality except for $\mathrm{SO}_{2}$, which showed negligible change.

\section{COVID-19 infection rate with Geo-meteorological parameters}

Meteorological factors are the key drivers for controlling infectious diseases in different parts of the world (Şahin 2020). However, these triggering factors may behave differently for the daily mortality cases in a different climatic zone. For example, in tropical Brazil, high mean temperature and intermediate relative humidity might be responsible for the COVID-19 outbreak (Auler et al. 2020). In Turkey, the key weather factors controlling the spread of COVID-19 are temperature $\left({ }^{\circ} \mathrm{C}\right)$, dew point $\left({ }^{\circ} \mathrm{C}\right)$, humidity (\%), and wind speed (mph). As the incubation period of COVID-19 varies from 1 day to 14 days, Spearman's correlation coefficients resulted in the highest correlations among population, wind speed, and temperature, respectively (Şahin 2020). In this present study, DEM ( $p<0.01)$, wind pressure $(p<0.01)$," LST $(p<0.04)$," rainfall $(p<0.01)$," and wind speed $(p<0.03)$ were significantly associated with the COVID-19 infection rate. (Wu et al. 2020b) revealed that land temperature and relative humidity were linked to the daily new cases and deaths of COVID-19. A $1^{\circ} \mathrm{C}$ increases in temperature and $1 \%$ increases in Relative Humidity was associated with reduced mortality rate by $3.08 \%$ and $0.85 \%$ reduction of daily new cases of COVID-19 infection. In this study a $1^{\circ} \mathrm{C}$ increase in temperature leads to a $10 \%$ increase in COVID-19 infection rates.

(Qi et al. 2020; Wu et al. 2020b) used a Generalized Additive Model (GAM) to compute the province-specific relations amongst climatological variables and the daily cases of COVID-19 in China. Their studies found that the temperature and humidity presented negative associations with the COVID-19, while a significant interaction can be found between temperature and humidity. This is different to our study because temperature had positive relationship with COVID-19 infection rates.

(Ma et al. 2020; Qi et al. 2020) established a relationship between daily death numbers of COVID-19 with meteorological parameters and air pollution data from 20 January 2020 to 29 February 2020 in Wuhan, China, which was the starting point of the global pandemic. They revealed a positive correlation $(r 2=0.44)$ between COVID-19 death and temperature. This is similar to our study because we had positive correlation between COVID-19 and temperature $(r 2=0.73)$

\section{COVID-19 infection rate with social parameters}

Page $11 / 19$ 
Population density is an important parameter that catalyzed the outbreak of COVID-19 infection (J and H 2020). (Dhaval 2020) showed that most of the areas having a high-density population have more confirmed COVID-19 cases. For analyzing COVID-19 data, population density information needs to be used as one of the controlling variables and it was suggested that investigation should be done at local, regional, and national levels separately (Pedrosa 2020). (Hu et al. 2013) calculated a relationship between influenza mortality rates and population densities in the USA and found that the higher density shows higher reported mortality. In the present study, population density $(p<0.01)$ ), brickfield density $(p<0.02)$, and poverty $(p<0.01)$ had high coefficients to COVID-19 infection rate.

In and around the Dhaka there are about 917 brickfields are covering 26.64 square kilometers (Hassan et al. 2019), which are the primary sources for air pollution in the city. These brickfields emit 23,300 tons from $\mathrm{PM}_{2.5}, 15,500$ tons of sulfur dioxide $\left(\mathrm{SO}_{2}\right), 302,000$ tons of carbon monoxide (CO), 6,000 tons of black carbon, and 1.8 million tons of $\mathrm{CO}_{2}$ (Guttikunda et al. 2013b). Several research reports mentioned that these brickfields not only affect the atmospheric quality of the city but also a responsible factor for other environmental pollutions and public health hazard (Imran et al. 2014; Saha and Hosain 2016; Skinder et al. 2014; Tusher et al. 2018; Zhang 1997). The strong correlation of brickfield density and COVID-19 infection rates indicated in this study is alarming in a city like Dhaka. Together with poverty and other environmental parameters, the situation is alarming for Dhaka as far as COVID-19 infection rates are concerned. With the government planning to resume all economic activities in the city, the level of air pollution will increase and this will have an increased effect on COVID-19 infection rates.

\section{Conclusion}

The spatial relationships between the COVID-19 infection rate and 17 independent parameters of air pollution, geometeorological, and social in the study area using Graphically Weighted Regression Model and GIS platform were studied. There were no significant statistical relationships between the COVID-19 infection rate and air pollution, geo-meteorological, and social parameters. From air pollution parameters $\mathrm{PM}_{2.5}(p<0.02), \mathrm{AOT}(p<0.01), \mathrm{CO}(p<0.05)$, water vapor $(p<0.01)$, and $\mathrm{O}_{3}(p<0.01)$ were highly correlated with COVID-19 infection rate while DEM $(p<0.01)$, wind pressure $(p<0.01)$," LST $(p<0.04)$," rainfall $(p<0.01)$ and wind speed $(p<0.03)$ of geo-meteorological parameters were associated with the COVID-19 attack. Moreover, population density $(p<0.01)$," brickfield density $(p<0.02)$," and poverty $(p<0.01)$ were highly coefficient as the key independent variables to the COVID-19 infection rate in the city. In addition to this, the government of Bangladesh can utilize these findings in order to formulate new rules and strategies for reducing infectious diseases like COVID-19. This study will be useful for all researchers who are working on understanding the latent and visible relationships between the COVID-19 and its associated variables. The methodology can be replicated to a similar country or region considering the local microclimatic environment. Studies with more variables including ecological, meteorological and social (GDP, BMI Global Health Index) variables will be vital to model and understand the spread of COVID-19.

\section{Declarations}

\section{Conflict of interest}

The authors declare that they have no conflict of interest.

\section{References}

1. Ahmed B, Hasan R, Maniruzzaman K (2014) Urban morphological change analysis of Dhaka city, Bangladesh, using space syntax ISPRS International Journal of Geo-Information 3:1412-1444

2. Ahmed B, Kamruzzaman M, Zhu X, Rahman M, Choi K (2013) Simulating land cover changes and their impacts on land surface temperature in Dhaka, Bangladesh Remote Sensing 5:5969-5998 
3. Auler A, Cássaro F, da Silva V, Pires L (2020) Evidence that high temperatures and intermediate relative humidity might favor the spread of COVID-19 in tropical climate: A case study for the most affected Brazilian cities Science of The Total Environment:139090

4. Babak O, Deutsch CV (2009) Statistical approach to inverse distance interpolation Stochastic Environmental Research and Risk Assessment 23:543-553 doi:10.1007/s00477-008-0226-6

5. Bangladesh - Urban population. (2019) Knoema. https://knoema.com/atlas/Bangladesh/Urban-population.

6. Bangladesh Covid-19 Update (2020) Institute of Epidemiology, Disease Control and Research (IEDCR). https://iedcr.gov.bd/index.php/component/content/article/73-ncov-2019.

7. Bangladesh Population. (2020) Worldometer.

8. https://worldometers.info/world-population/bangladesh-population/.

9. Bashir MF, Ma B, Bilal, Komal B, Bashir MA, Tan D, Bashir M (2020) Correlation between climate indicators and COVID-19 pandemic in New York, USA Science of the Total Environment:16-16 doi:10.1016/j.scitotenv.2020.138835

10. Begum BA, Hopke PK, Markwitz A (2013) Air pollution by fine particulate matter in Bangladesh Atmospheric Pollution Research 4:75-86

11. BMD (2016) Bangladesh Meteorological Department. Bangladesh Meteorological Department,

12. Bontempi E (2020) First data analysis about possible COVID-19 virus airborne diffusion due to air particulate matter (PM): The case of Lombardy (Italy) Environmental Research 186:20-20 doi:10.1016/j.envres.2020.109639

13. Brunsdon C, Fotheringham AS, Charlton ME (1996) Geographically weighted regression: a method for exploring spatial nonstationarity Geographical analysis 28:281-298

14. Casanova LM, Jeon S, Rutala WA, Weber DJ, Sobsey MD (2010) Effects of air temperature and relative humidity on coronavirus survival on surfaces Applied and Environmental Microbiology 76:2712-2717 doi:10.1128/AEM.02291-09

15. Ceccato P, Ramirez B, Manyangadze T, Gwakisa P, Thomson MC (2018) Data and tools to integrate climate and environmental information into public health Infectious Diseases of Poverty 7:1-11 doi:10.1186/s40249-018-0501-9

16. Charlton M, Fotheringham S, Brunsdon C (2009) Geographically weighted regression White paper National Centre for Geocomputation National University of Ireland Maynooth

17. Chen FW, Liu CW (2012) Estimation of the spatial rainfall distribution using inverse distance weighting (IDW) in the middle of Taiwan Paddy and Water Environment 10:209-222 doi:10.1007/s10333-012-0319-1

18. Conticini E, Frediani B, Caro D (2020) Can atmospheric pollution be considered a co-factor in extremely high level of SARS-CoV-2 lethality in Northern Italy? Environmental pollution:114465

19. Dhaval D (2020) Urban Densities and the Covid-19 Pandemic : Upending the Sustainability Myth of Global Megacities. Observer Research Foundation.,

20. Domingo JL, Rovira J (2020) Effects of air pollutants on the transmission and severity of respiratory viral infections Environmental Research:109650

21. Engel-Cox JA, Holloman CH, Coutant BW, Hoff RM (2004) Qualitative and quantitative evaluation of MODIS satellite sensor data for regional and urban scale air quality Atmospheric environment 38:2495-2509

22. Esri (2020) How IDW works:2020-2020

23. Fotheringham AS, Charlton ME, Brunsdon C (1998) Geographically weighted regression: a natural evolution of the expansion method for spatial data analysis Environment and planning A 30:1905-1927

24. Franke R (1982) Scattered Data Interpolation: Tests of Some Method Mathematics of Computation 38:181-181 doi:10.2307/2007474

25. Gorbalenya AE (2020) Severe acute respiratory syndrome-related coronavirus-The species and its viruses, a statement of the Coronavirus Study Group BioRxiv 
26. Guan W-j et al. (2020) Clinical characteristics of coronavirus disease 2019 in China New England journal of medicine 382:1708-1720

27. Guttikunda SK, Begum BA, Wadud Z (2013a) Particulate pollution from brick kiln clusters in the Greater Dhaka region, Bangladesh Air Quality, Atmosphere \& Health 6:357-365

28. Guttikunda SK, Begum BA, Wadud Z (2013b) Particulate pollution from brick kiln clusters in the Greater Dhaka region, Bangladesh Air Quality, Atmosphere and Health 6:357-365 doi:10.1007/s11869-012-0187-2

29. Hassan MM, Juhász L, Southworth J (2019) Mapping Time-Space Brickfield Development Dynamics in Peri-Urban Area of Dhaka, Bangladesh ISPRS International Journal of Geo-Information 8:447

30. He MZ et al. (2020) Short- and intermediate-term exposure to NO2 and mortality: A multi-county analysis in China Environmental Pollution 261:114165-114165 doi:10.1016/j.envpol.2020.114165

31. Hoque MA, Hoque MM, Ahmed KM (2007) Declining groundwater level and aquifer dewatering in Dhaka metropolitan area, Bangladesh: causes and quantification Hydrogeology Journal 15:1523-1534

32. Hu H, Nigmatulina K, Eckhoff P (2013) The scaling of contact rates with population density for the infectious disease models Mathematical Biosciences 244:125-134 doi:10.1016/j.mbs.2013.04.013

33. Huang C et al. (2020) Clinical features of patients infected with 2019 novel coronavirus in Wuhan, China The lancet 395:497-506

34. Imran M, Baten M, Nahar B, Morshed N (2014) Carbon dioxide emission from brickfields around Bangladesh International Journal of Agricultural Research, Innovation and Technology 4:70-75

35. J R, H S (2020) High population densities catalyze the spread of COVID-19 Journal of Travel Medicine:2-2 doi:https://doi.org/10.1093/jtm/taaa038

36. Johns Hopkins University (2020) Coronavirus Resource Center. https://coronavirus.jhu.edu/map.html. Accessed 20 May 2020

37. Leung Y, Mei C-L, Zhang W-X (2000) Statistical tests for spatial nonstationarity based on the geographically weighted regression model Environment and Planning A 32:9-32

38. Luo W, Majumder MS, Liu D, Poirier C, Mandl KD, Lipsitch M, Santillana M (2020) The role of absolute humidity on transmission rates of the COVID-19 outbreak medRxiv:7-7 doi:10.1101/2020.02.12.20022467

39. Ma Y et al. (2020) Effects of temperature variation and humidity on the death of COVID-19 in Wuhan, China Science of the Total Environment 724:138226-138226 doi:10.1016/j.scitotenv.2020.138226

40. Manisalidis I, Stavropoulou E, Stavropoulos A, Bezirtzoglou E (2020) Environmental and Health Impacts of Air Pollution: A Review Frontiers in Public Health 8

41. Martelletti L, Martelletti P (2020) Air pollution and the novel Covid-19 disease: a putative disease risk factor SN Comprehensive Clinical Medicine:1-5

42. Nazrul Islam SSAME (2020) Temperature, humidity, and wind speed are associated with lower Covid-19 incidence medRxiv:8-11

43. Ogen Y (2020) Assessing nitrogen dioxide (NO2) levels as a contributing factor to the coronavirus (COVID-19) fatality rate Science of The Total Environment:138605

44. Ortiz C, Linares C, Carmona R, Díaz J (2017) Evaluation of short-term mortality attributable to particulate matter pollution in Spain Environmental Pollution 224:541-551 doi:10.1016/j.envpol.2017.02.037

45. Pedrosa RH (2020) The dynamics of Covid-19: weather, demographics and infection timeline medRxiv

46. Qi H et al. (2020) COVID-19 transmission in Mainland China is associated with temperature and humidity: A time-series analysis Science of the Total Environment 728:138778-138778 doi:10.1016/j.scitotenv.2020.138778

47. Saha CK, Hosain J (2016) Impact of brick kilning industry in peri-urban Bangladesh International Journal of Environmental Studies 73:491-501 doi:10.1080/00207233.2016.1179014 
48. Şahin M (2020) Impact of weather on COVID-19 pandemic in Turkey Science of the Total Environment 728 doi:10.1016/j.scitotenv.2020.138810

49. Sajadi MM, Habibzadeh P, Vintzileos A, Shokouhi S, Miralles-Wilhelm F, Anthony A (2020) Temperature, Humidity and Latitude Analysis to Predict Potential Spread and Seasonality for COVID-19 SSRN:18-18

50. Sharma S, Zhang M, Anshika, Gao J, Zhang H, Kota SH (2020) Effect of restricted emissions during COVID-19 on air quality in India Science of the Total Environment 728:138878-138878 doi:10.1016/j.scitotenv.2020.138878

51. Shepard D (1968) Two- dimensional interpolation function for irregularly- spaced data Proc 23rd Nat Conf:517-524 doi:10.1145/800186.810616

52. Shibli DA (2019) Dhaka and the cities of the future.

53. Skinder BM, Sheikh AKPAQ, Bashir Ahmad G (2014) Brick kilns: Cause of Atmospheric Pollution Journal of Pollution Effects \& Control 02:7-7 doi:10.4172/2375-4397.1000112

54. Tusher TR, Ashraf Z, Akter S (2018) Health effects of brick kiln operations: A study on largest brick kiln cluster in Bangladesh South East Asia Journal of Public Health 8:32-36

55. Wheeler DC, Páez A (2010) Geographically weighted regression. In: Handbook of applied spatial analysis. Springer, pp 461-486

56. World Health Organization (2020). World Health Organization

57. Wu X, Nethery RC, Sabath BM, Braun D, Dominici F (2020a) Exposure to air pollution and COVID-19 mortality in the United States medRxiv

58. Wu Y et al. (2020b) Effects of temperature and humidity on the daily new cases and new deaths of COVID-19 in 166 countries Science of the Total Environment 729 doi:10.1016/j.scitotenv.2020.139051

59. Xie J, Zhu Y (2020) Association between ambient temperature and COVID-19 infection in 122 cities from China Science of the Total Environment 724:138201-138201 doi:10.1016/j.scitotenv.2020.138201

60. Zhang Z (1997) Energy efficiency and environmental pollution of brickmaking in China Energy 22:33-42 doi:10.1016/S0360-5442(96)00078-3

\section{Figures}



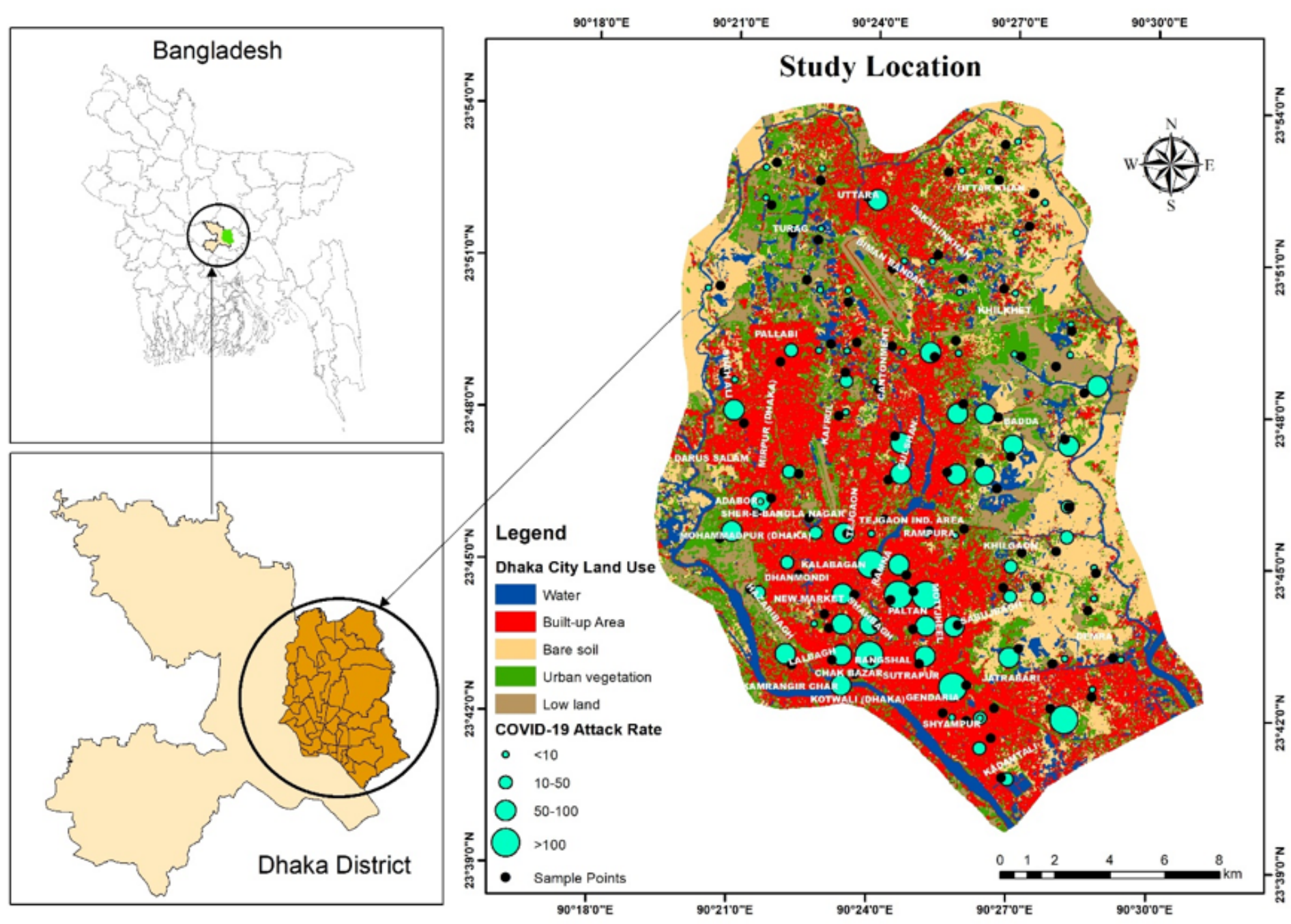

Figure 1

The geographical location and distribution of COVID-19 infection in Dhaka city. Per Cyan dot means the ratio of infection rate on land use map. It is observed that the middle and southern parts of the city were the most affected zones due to COVID-19. The small black dot means the sample points to collect different parameters of air pollution and geometeorological data.

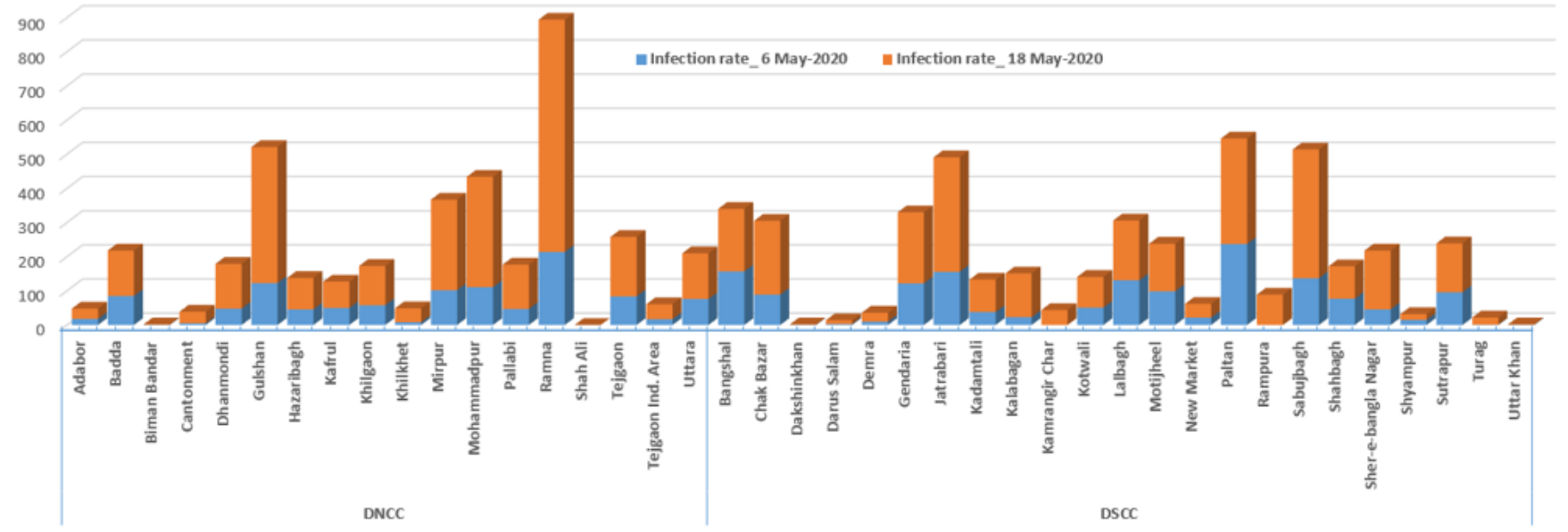




\section{Figure 2}

Location-wise confirmed COVID-19 cases in both Dhaka North City and Dhaka South City Corporations (Bangladesh Covid19 Update 2020).
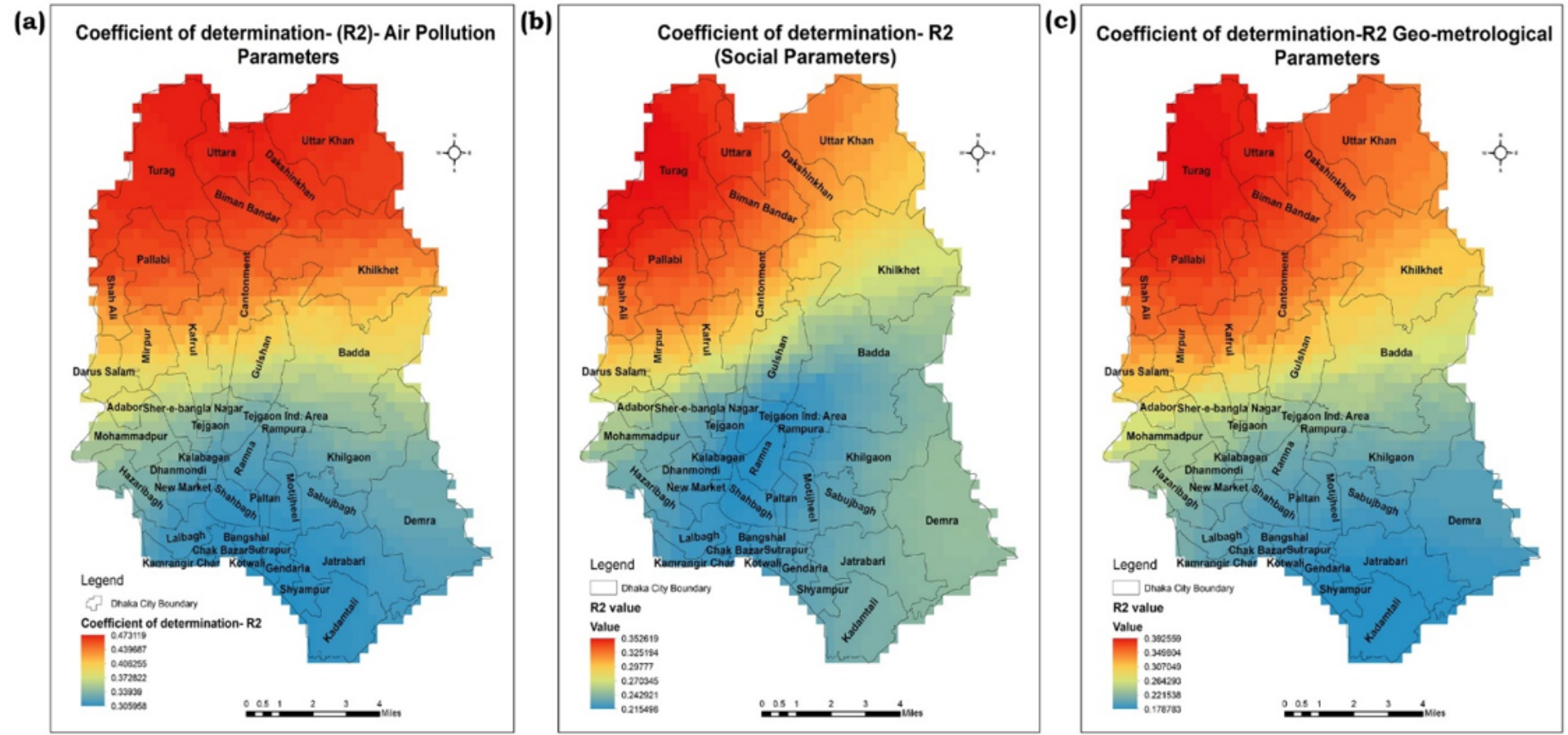

\section{Figure 3}

Spatial distribution of $\mathrm{r} 2$ in air pollution, social and geo-meteorological parameters
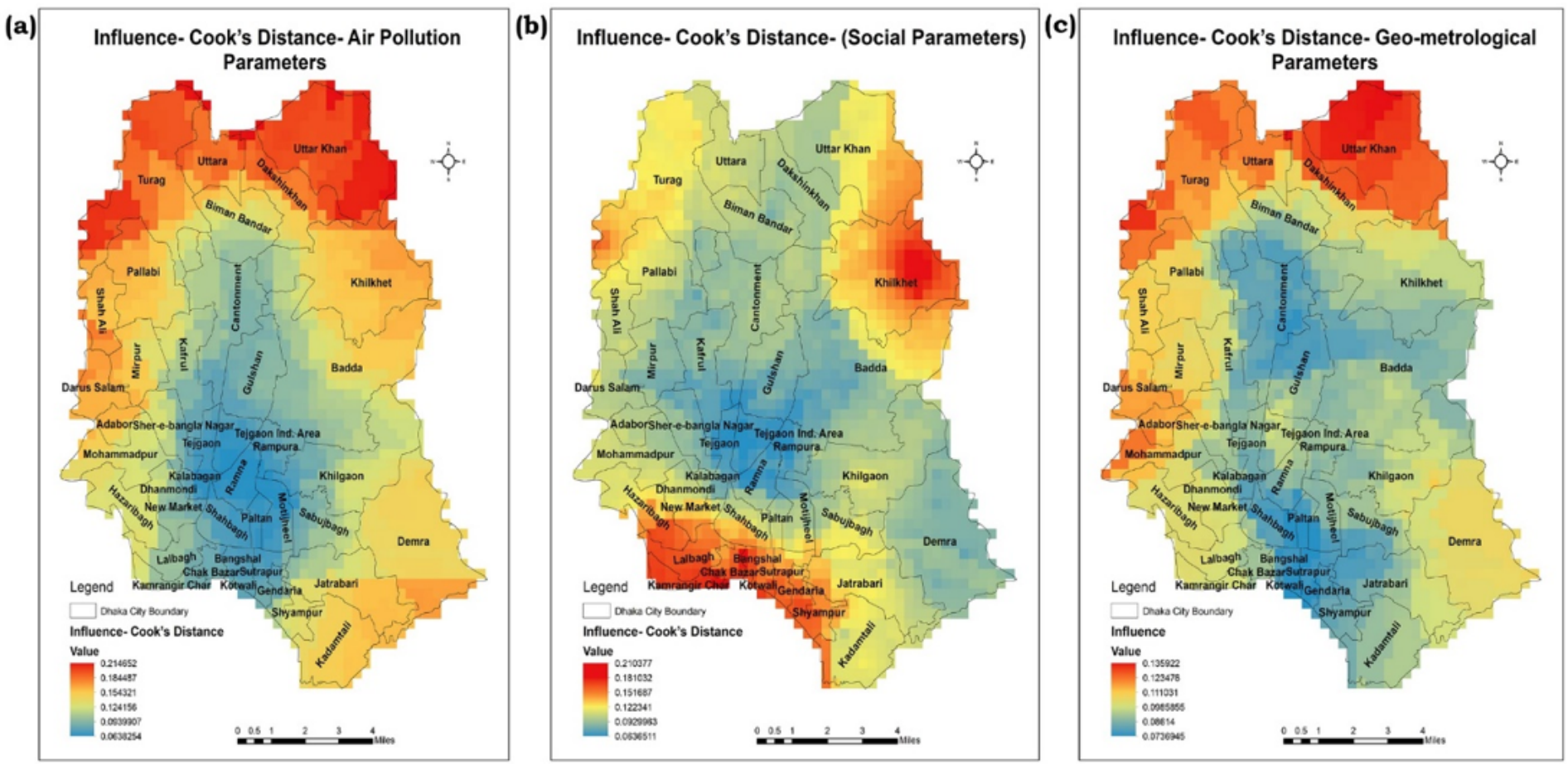

Figure 4 
Spatial distribution of influence in air pollution, social and geo-meteorological parameters
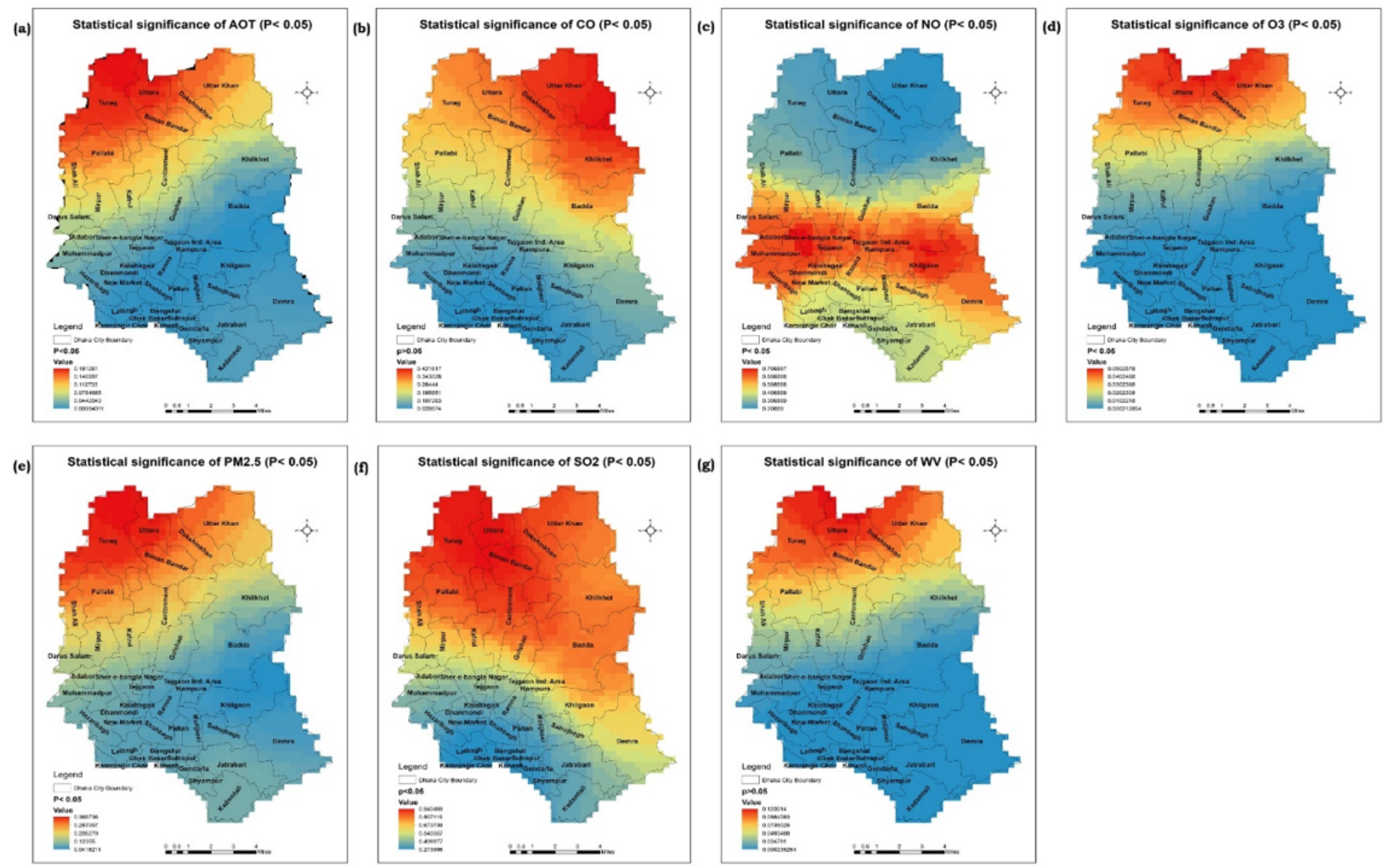

\section{Figure 5}

Spatial distribution of $\mathrm{p}$-value in air pollution parameters
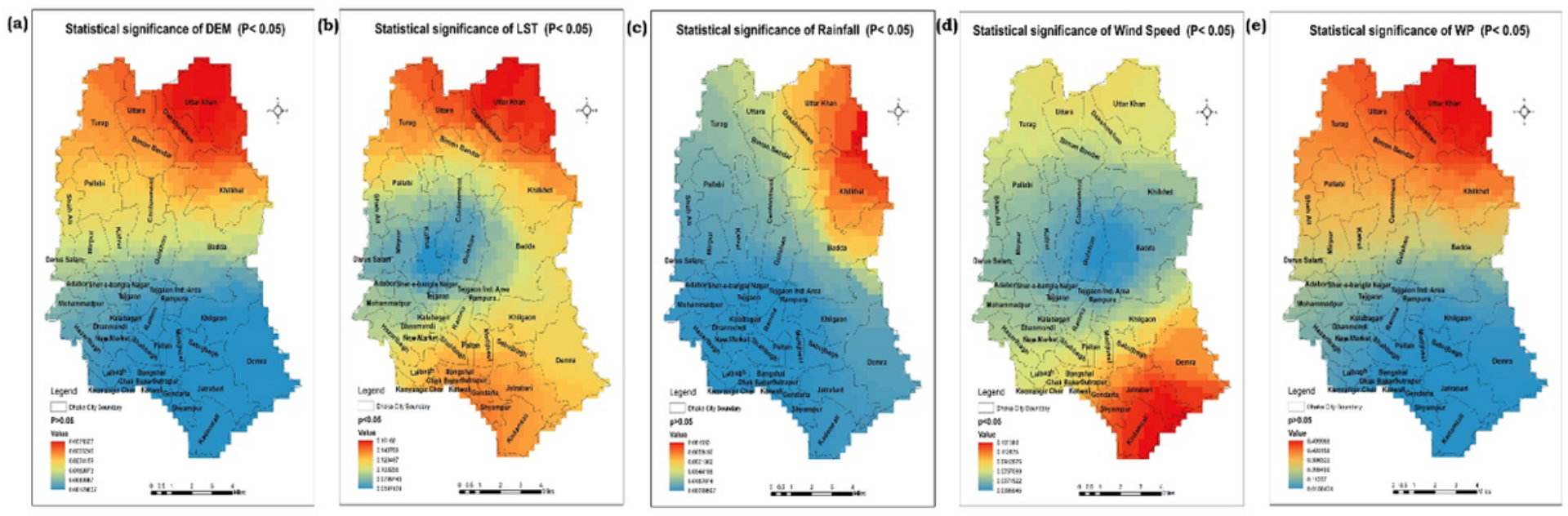

Figure 6

Spatial distribution of p-value in geo-Meteorological parameters 
(a)
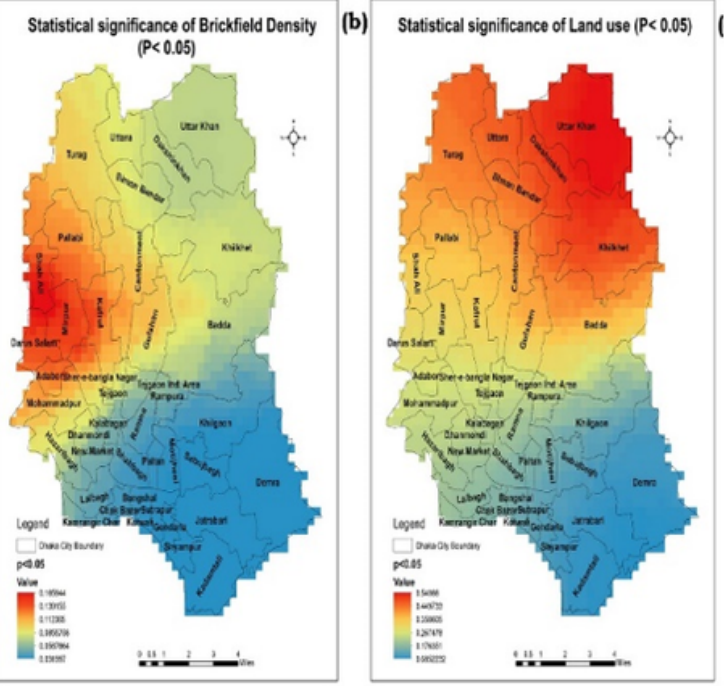

(c)

Statistical significance of Literacy $(P<0.05)$

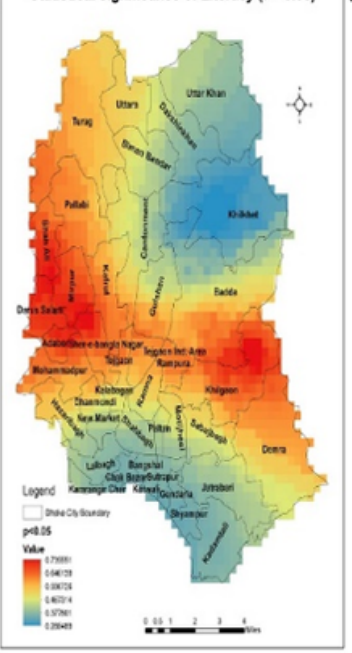

(d) Statistical significance of Pop Density $(P<0.05)$
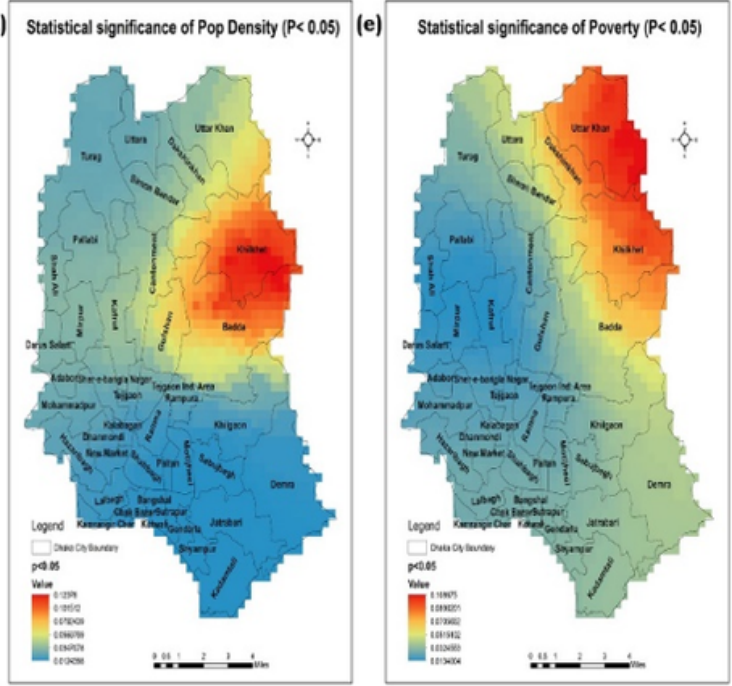

Figure 7

Spatial distribution of $p$-value in social parameters 